\title{
Methodological comparison of the allele refractory mutation system and direct sequencing for detecting EGFR mutations in NSCLC, and the association of EGFR mutations with patient characteristics
}

\author{
MINMIN WU ${ }^{1}, X$ IAODONG PAN ${ }^{2}$, YAYA XU $^{2}$, SIYING WU ${ }^{3}$, XIULING WU ${ }^{3}$ and BICHENG CHEN \\ Departments of ${ }^{1}$ Surgery, ${ }^{2}$ Transplantation Laboratory and ${ }^{3}$ Pathology, The First Affiliated Hospital of \\ Wenzhou Medical University, Wenzhou, Zhejiang 325000, P.R. China
}

Received March 18, 2017; Accepted November 2, 2017

DOI: $10.3892 / \mathrm{ol} .2018 .8775$

\begin{abstract}
Gefitinib is effective for patients with non-small cell lung cancer (NSCLC) with a mutation in the epidermal growth factor receptor (EGFR) gene, which makes the detection of EGFR mutations a critical step prior to determining a treatment schedule. Therefore, the present study determined the EGFR mutation status in patients with NSCLC using an allele refractory mutation system (ARMS) and analyzed the detection ratio for different specimen types. A total of 1,596 NSCLS samples were collected and EGFR gene mutations were detected on exons 18-21 using ARMS and direct sequencing. The concordance of two methods reached $89.21 \%$, with a total mutation rate of $45.55 \%(727 / 1,596)$, in which the mutation rate in lung adenocarcinoma samples was markedly increased compared with squamous cell carcinoma (51.77 vs. 8.68\%). In patients with lung adenocarcinoma, EGFR mutations were more frequent in female patients than male patients $(65.53$ vs. $39.80 \%, \mathrm{P}<0.01)$; there was no observable difference depending on age. Similar results were obtained for squamous cell carcinoma. In the present study, certain rare mutations were also identified; these may be subjects for further study. The impact of different sample types on the consistency between the methods was determined to be insignificant. ARMS is a more applicable approach for large-scale clinical detection than direct sequencing, and we hypothesize that ARMS may replace direct sequencing if the drawbacks of ARMS, including its narrow detection range, can be amended.
\end{abstract}

Correspondence to: Dr Bicheng Chen, Department of Surgery, The First Affiliated Hospital of Wenzhou Medical University, 2 Fuxue Lane, Wenzhou, Zhejiang 325000, P.R. China

E-mail: bisonch@163.com

Key words: non-small cell lung cancer, epidermal growth factor receptor, amplification refractory mutation system, direct sequencing method, mutation rate

\section{Introduction}

Lung cancer is one of the most common types of malignant tumor and threatens the health and survival of human beings (1). The majority of cases of lung cancer are non-small cell lung cancer (NSCLC; 80\%), which is associated with $~ 400,000$ mortalities annually, a generally poor prognosis and a difficulty of diagnosing in the early stages (2-4). The development of lung cancer is often due to environmental or lifestyle factors including smoking, environmental pollution and occupational exposure to carcinogens. These factors may induce mutations in susceptible genes and epigenetic changes, ultimately resulting in the lung cancer (5).

Among genes that are commonly mutated in NSCLC, including TP53, epidermal growth factor receptor (EGFR) and KRAS, the detection of EGFR mutations is the most common (6). EGFR, a transmembrane tyrosine kinase receptor, includes an intracellular tyrosine kinase domain, and an extracellular domain with a high affinity for epidermal growth factor. EGFR regulates a number of biological activities, including cell proliferation, differentiation, migration and the promotion of cell survival (7). Therefore, when EGFR is abnormally expressed, cells may rapidly proliferate and differentiate, potentially leading to the formation of a tumor. A previous study reported that $48-80 \%$ of cases of NSCLC exhibit abnormal EGFR expression (8).

At present, small-molecule therapeutic agents, including gefitinib, erlotinib, cetuximab and bevacizumab, have been applied as a molecularly-targeted treatment against tumors. These agents have been demonstrated to be suitable for the treatment of patients with NSCLC in previous studies $(3,9,10)$. Other previous studies concluded that patients with NSCLC with EGFR mutations receiving EGFR-TKI treatment experienced an increased median progression-free survival time compared with patients treated with conventional chemotherapy, with a difference of $\sim 8$ months $(10,11)$. Thus, it is important to develop a low-cost, accurate and efficient method for the clinical detection of EGFR mutations.

Various detection methods are currently used in the clinic, including capillary electrophoresis (12), denaturing high-performance liquid chromatography (13), high-resolution 
melting analysis (14), quantitative polymerase chain reaction (PCR) analysis (15) and PCR single-strand conformation polymorphism (16). However, these methods may be expensive and time-consuming, require large samples, and produce hazardous substances during detection. Consequently, there are no methods that are completely suited to replace the direct sequencing method. As the current gold standard for clinical detection, the direct sequencing method has several limitations due to technical and methodological issues; however, it is accurate, reliable and capable of detecting almost every mutation of EGFR. The allele refractory mutation system (ARMS), a highly selective and sensitive approach that can detect 29 types of EGFR mutation in a reduced number of samples, has been applied in clinical and laboratory settings. In the present study, ARMS was compared with direct sequencing to identify which is the most appropriate method for detection in the clinic.

\section{Materials and methods}

Sample collection. The present study was approved by the First Affiliated Hospital of Wenzhou Medical University (Wenzhou, China). Written informed consent was obtained from all patients. Samples were collected from 1,596 patients with NSCLC who had been diagnosed in The First Affiliated Hospital of Wenzhou Medical University between July 2011 and June 2016. Exons 18-21 of the EGFR genes were analyzed using the ARMS and direct sequencing methods. All samples were successfully analyzed using the ARMS method, whereas $\sim 1,140$ were successfully analyzed using the direct sequencing method (direct sequencing failed for 91 samples due to technical issues, and 365 samples were of insufficient quantity for direct sequencing). There were 1,329 adenocarcinoma samples, 217 squamous cell carcinoma samples and 19 adenosquamous cell carcinoma samples; the pathology type of 31 samples was unknown. There were 922 male and 674 female patients, with an age range of 18-89 and a mean age of 64 years.

DNA extraction. The samples were collected using 3 different methods: Biopsy, surgical resection and hydrothoracic or ascitic fluid extraction. The samples were paraffin-embedded and DNA was extracted and purified using the AmoyDx ${ }^{\circledR}$ FFPE DNA Extraction kit (cat. no. ADx-FF01; Amoy Diagnostics Co., Ltd., Xiamen, China) according to the manufacturer's instructions.

EGFR gene analysis with ARMS. Following the determination of the DNA concentration, by ultraviolet spectrophotometry, EGFR gene mutations were analyzed using the AmoyDx ${ }^{\circledR}$ EGFR 29 Mutations Detection kit (cat. no. ADx-EG0X; Amoy Diagnostics Co., Ltd.) according to the manufacturer's instructions on a LightCycler480 II (Roche Diagnostics, Basel, Switzerland). Fluorescence calibration was performed on a LightCycler480 I (Roche Diagnostics).

The results of the mutation assay were analyzed based on different mutant $\mathrm{C}_{\mathrm{q}}$ values (Table I).

Strong positive. If the sample $\mathrm{C}_{\mathrm{q}}$ value was $<26$, then the sample was classified as strong positive.
Weak positive. If the sample $\mathrm{C}_{\mathrm{q}}$ value ranged between 26 and 29 , the sample was provisionally classified as weak positive and the $\Delta \mathrm{C}_{\mathrm{q}}$ of the reaction tube was calculated to confirm the result. If the $\Delta \mathrm{C}_{\mathrm{q}}$ value was less than the corresponding threshold value of $\Delta \mathrm{C}_{\mathrm{q}}$, the sample was confirmed as weak positive. If the $\Delta \mathrm{C}_{\mathrm{q}}$ value was greater than the cut-off $\Delta \mathrm{C}_{\mathrm{q}}$ value, the sample was classified as negative or below the detection limit of the kit. $\Delta \mathrm{C}_{\mathrm{q}}$ was calculated as follows: $\Delta \mathrm{C}_{\mathrm{q}}=$ mutant $\mathrm{C}_{\mathrm{q}}$ value - external control $\mathrm{C}_{\mathrm{q}}$ value.

Negative. If the sample amplification signal $\mathrm{C}_{\mathrm{q}}$ value was $\geq$ the critical negative value presented in the 'Negative' row in Table I, then the sample was classified as negative or below the detection limit of the kit.

DNA direct sequencing. A total of 1,140 samples-examined using direct sequencing method were examined using the direct sequencing method for comparison with the ARMS method. The primers were designed by Shanghai Shenggong Biology Engineering Technology Service, Ltd. (Shanghai, China; Table II). A BigDye ${ }^{\mathrm{TM}}$ Terminator v1.1 Cycle Sequencing kit was applied in the detection, the total reaction system contained $10 \mathrm{ng}$ of purified PCR product, $8 \mu \mathrm{l}$ of BigDye (2.5X; Beijing Think-Far Technology Co., Ltd., Beijing, China), 3.2 pmol of primers and $10 \mu \mathrm{l}$ aseptic deionized water. The PCR reaction conditions included an initial denaturation at $95^{\circ} \mathrm{C}$ for $1 \mathrm{~min}$, followed by 25 cycles at $94^{\circ} \mathrm{C}$ for $10 \mathrm{sec}$ and $50^{\circ} \mathrm{C}$ for $5 \mathrm{sec}$, then $60^{\circ} \mathrm{C}$ for $4 \mathrm{~min}$. Subsequently, the products were purified using ExoSap-IT reagent (Thermo Fisher Scientific, Inc., Waltham, MA, USA), and the reaction was terminated using BigDye Terminator v1.1 (cat. no. 4337449; Beijing Think-Far Technology Co., Ltd.) according to the manufacturer's instructions. All sequence data was analyzed using Sequencher $4.6^{\circledR}$ (Gene Codes Corporation, Ann Arbor, MI, USA) and all positive results were detected a second time for confirmation.

Data analysis. Following data collection and tissue classification, a corresponding line chart was constructed according to the year of tissue collection (Fig. 1; Cohen's $\kappa$ coefficient was calculated using SPSS (version 16.0 for Windows; SPSS, Inc., Chicago, IL, USA) to examine the consistency of the detection results between ARMS and direct sequencing. A $\kappa$-value between 0.40 and 0.75 was considered to represent a good consistency level, and a $\kappa$-value $>0.75$ was considered to represent a high consistency level. Subsequently, the influences of different sample types on consistency and the association between EGFR gene mutation with age and sex were examined using the $\chi^{2}$ test in SPSS (version 16.0 for Windows; SPSS, Inc., Chicago, IL, USA). $\mathrm{P}<0.05$ was considered to indicate a statistically significant difference. GraphPad Prism software (version 5.0; GraphPad Software, Inc., La Jolla, CA, USA) was used to produce the figures.

\section{Results}

Analysis of the patients diagnosed with NSCLC. The patients diagnosed in The First Affiliated Hospital of Wenzhou Medical University were classified into three types according to their pathology, including adenocarcinoma, squamous cell carcinoma and adenosquamous cell 
Table I. Definition of $\mathrm{C}_{\mathrm{q}}$ thresholds for strong positive, weak positive and negative EGFR mutation detection status.

\begin{tabular}{llccccccc}
\hline Strong positive & \multicolumn{1}{c}{ Strong positive } & 19Del & L858R & T790M & Insertions & G791X & S786I & L861Q \\
\hline Strong positive & Mutant $\mathrm{C}_{\mathrm{q}}$ value & $\mathrm{C}_{\mathrm{q}}<26$ & $\mathrm{C}_{\mathrm{q}}<26$ & $\mathrm{C}_{\mathrm{q}}<26$ & $\mathrm{C}_{\mathrm{q}}<26$ & $\mathrm{C}_{\mathrm{q}}<26$ & $\mathrm{C}_{\mathrm{q}}<26$ & $\mathrm{C}_{\mathrm{q}}<26$ \\
Weak positive & Mutant $\mathrm{C}_{\mathrm{q}}$ value & $26 \leq \mathrm{C}_{\mathrm{q}}<29$ & $26 \leq \mathrm{C}_{\mathrm{q}}<29$ & $26 \leq \mathrm{C}_{\mathrm{q}}<29$ & $26 \leq \mathrm{C}_{\mathrm{q}}<29$ & $26 \leq \mathrm{C}_{\mathrm{q}}<29$ & $26 \leq \mathrm{C}_{\mathrm{q}}<29$ & $26 \leq \mathrm{C}_{\mathrm{q}}<29$ \\
& $\Delta \mathrm{C}_{\mathrm{q}}$ threshold value & 12 & 11 & 7 & 9 & 7 & 8 & 8 \\
Negative & Mutant $\mathrm{C}_{\mathrm{q}}$ value & $\mathrm{C}_{\mathrm{q}} \geq 29$ & $\mathrm{C}_{\mathrm{q}} \geq 29$ & $\mathrm{C}_{\mathrm{q}} \geq 29$ & $\mathrm{C}_{\mathrm{q}} \geq 29$ & $\mathrm{C}_{\mathrm{q}} \geq 29$ & $\mathrm{C}_{\mathrm{q}} \geq 29$ & $\mathrm{C}_{\mathrm{q}} \geq 29$
\end{tabular}

$\mathrm{C}_{\mathrm{q}}$, cycle threshold; $\Delta \mathrm{C}_{\mathrm{q}}$, mutant $\mathrm{C}_{\mathrm{q}}$ minus control $\mathrm{C}_{\mathrm{q}}$.

Table II. Primer sequences for direct sequencing by polymerase chain reaction.

\begin{tabular}{|c|c|}
\hline Target & Sequence \\
\hline \multicolumn{2}{|l|}{ Exon 18} \\
\hline Sense $\left(5^{\prime}-3^{\prime}\right)$ & $\begin{array}{l}\text { TGTCCTGGCACCCAAGCCCA } \\
\text { TGCCGTGGCT }\end{array}$ \\
\hline Antisense (5'-3') & $\begin{array}{l}\text { GTGGGGAGCCCAGAGTCCTT } \\
\text { GCAAGCTGTATA }\end{array}$ \\
\hline \multicolumn{2}{|l|}{ Exon 19} \\
\hline Sense $\left(5^{\prime}-3^{\prime}\right)$ & $\begin{array}{l}\text { CAGTGTCCCTCACCTTCGGG } \\
\text { GTGCATCGCT }\end{array}$ \\
\hline Antisense (5'-3') & $\begin{array}{l}\text { ААCCTCAGGCCCACCTTTT } \\
\text { СТCATGTCTGG }\end{array}$ \\
\hline \multicolumn{2}{|l|}{ Exon 20} \\
\hline Sense $\left(5^{\prime}-3^{\prime}\right)$ & $\begin{array}{l}\text { GCCCTGCGTAAACGTCCCTG } \\
\text { TGCTAGGTCT }\end{array}$ \\
\hline Antisense (5'-3') & $\begin{array}{l}\text { CACATGCGGTCTGCGCTCCT } \\
\text { GGGATAGCAA }\end{array}$ \\
\hline \multicolumn{2}{|l|}{ Exon 21} \\
\hline Sense $\left(5^{\prime}-3^{\prime}\right)$ & $\begin{array}{l}\text { CCATTCTTTGGATCAGTAGT } \\
\text { CACTAACGT }\end{array}$ \\
\hline Antisense (5'-3') & $\begin{array}{l}\text { CCAGGCTGCCTTCCCACTAG } \\
\text { CTGTATTG }\end{array}$ \\
\hline
\end{tabular}

carcinoma (Fig. 1; Table III). Adenocarcinoma was the most common and squamous cell carcinoma second most common, followed by adenosquamous cell carcinoma. It was also identified that the total number of NSCLC cases exhibited an increasing incidence, with fewer patients diagnosed in 2011 than 2016. Data was only collected until June 2016 and the data for 2016 in Fig. 1 was extrapolated from previous years; the tendency towards an increasing incidence rate may be more apparent from the actual data.

Comparison of the detection outcome between ARMS and direct sequencing. From 1,596 patients with NSCLC, 1,596 cases were analyzed using ARMS, but direct sequencing was successful for 1,140 samples (in the failed cases, exons 19-21 were complete in 22 samples, partially complete in 48 cases, and insufficient in 2 cases; Table IV). Among the 1,140 cases analyzed with both methods, 1,017 samples had

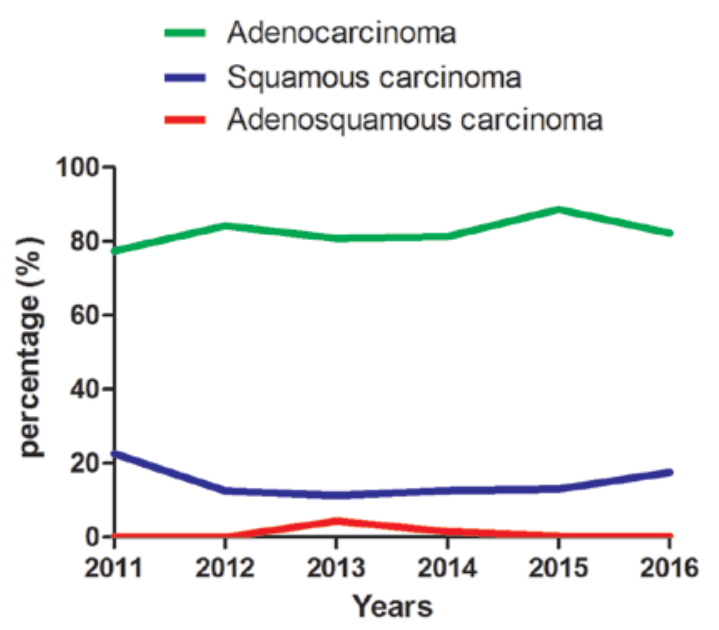

Figure 1. Summary of the pathology type of all patients with non-small cell lung cancer diagnosed at The First Affiliated Hospital of Wenzhou Medical University over 6 years. Although a number of patients were diagnosed twice in the time period, only the first diagnosis is presented in this figure.

consistent detection outcomes between the two methods; of the inconsistent samples, 77 cases were detected as wild-type individuals using the direct sequencing method and subsequently detected as mutants using ARMS, whereas 46 samples were identified as wild-type by ARMS and mutants by direct sequencing. Thus, the consistency was adequate, with a concordance rate of $89.21 \%(\mathrm{P}=0.007, \kappa=0.775$; Table II). Furthermore, the positive rate of ARMS (40.96\%) was marginally increased compared with that obtained with direct sequencing $(38.25 \%)$.

EGFR mutation rate and the association between mutations and population characteristics

EGFR mutation in all disease subtypes. A total of 12 types of mutation were detected in the present study, including 3 (G719A, G719S and G719C) in exon 18, 4 [exon 19 deletion (19Del), L747-T751Del, L747-A750>P and E746-S752>V] in exon 19, 3 (T790M, S768I and an unknown mutation accounting for 14 cases) in exon 20, and 2 (L858R and L861Q) in exon 21. A combination of mutations was observed in a number of cases (Table V); the mutations in 25 cases were caused by previously unidentified DNA alterations (Table VI). Among the 1,596 cases, mutations in EGFR were identified in 727 cases; thus, the total mutation rate was $45.55 \%(727 / 1,596)$. The mutations 19Del and L858R were the most common, accounting for 319 and 320 cases respectively, with mutation 
Table III. Summary of the pathology type of all patients with non-small cell lung cancer diagnosed at The First Affiliated Hospital of Wenzhou Medical University over 6 years.

\begin{tabular}{lccccccc}
\hline & \multicolumn{7}{c}{ Years, n (\%) } \\
\cline { 2 - 6 } Pathology type & 2011 & 2012 & 2013 & 2014 & 2015 & 2016 & Total, n (\%) \\
\hline Adenocarcinoma & $24(77.4)$ & $128(84.21)$ & $164(80.8)$ & $322(81.3)$ & $433(88.6)$ & $258(82.2)$ & $1,329(83.2)$ \\
Squamous cell carcinoma & $7(22.6)$ & $19(12.5)$ & $23(11.3)$ & $50(12.6)$ & $65(13.0)$ & $55(17.5)$ & $219(13.7)$ \\
Adenosquamous cell carcinoma & $0(0)$ & $1(0.07)$ & $9(4.4)$ & $6(1.5)$ & $2(0.4)$ & $1(0.3)$ & $19(1.2)$ \\
Other types & $0(0)$ & $4(2.63)$ & $7(3.4)$ & $18(4.5)$ & $0(0.00)$ & $0(0)$ & $29(1.7)$ \\
Total & 31 & 152 & 203 & 396 & 500 & 314 & 1,596 \\
\hline
\end{tabular}

Table IV. Consistency of ARMS and direct sequencing methods for different sample types.

\begin{tabular}{lrrrr}
\hline & \multicolumn{4}{c}{ Sample type } \\
\cline { 2 - 4 } Outcome & 659 & 271 & 77 & 1,007 \\
\hline Consistent & 88 & 24 & 11 & 122 \\
Inconsistent & 33 & 9 & 4 & 45 \\
ARMS(-) sequencing(+) & 55 & 15 & 7 & 77 \\
ARMS(+) sequencing(-) & 55 & & \\
Direct sequencing failure & 34 & 25 & 9 & 68 \\
\hline
\end{tabular}

Consistency of biopsy vs. surgery, $\chi^{2}=2.919, P=0.052$. ARMS, amplification refractory mutation system.

Table V. Frequency of simultaneous mutations.

\begin{tabular}{lc}
\hline Mutation type & Cases, $\mathrm{n}$ \\
\hline 19Del + L858R & 13 \\
19Del + T790M & 8 \\
L858R + T790M & 8 \\
20Ins + L858R & 1 \\
G719X + L861Q & 4 \\
G719 + S768I & 2 \\
\hline
\end{tabular}

Del, deletion; Ins, insertion.

rates of $43.88 \%(319 / 727)$ and $44.02 \%$ (320/727) respectively. Lung adenocarcinoma and squamous cell carcinoma had mutation rates of $51.77(688 / 1,329)$ and $8.68 \%(19 / 219)$ respectively. As lung adenocarcinoma and squamous cell carcinoma were the dominant types of NSCLC in the data, further analysis considered these subtypes separately.

EGFR mutation in lung adenocarcinoma. As presented in Table VII, lung adenocarcinoma accounted for 1,329 cases, of which 688 cases, including 283 male and 405 female patients, exhibited EGFR mutations. The difference in the mutation rate between male and female patients with
Table VI. Rare mutations detected in 25 patients using the direct sequencing method.

\begin{tabular}{lc}
\hline Mutation type & Cases \\
\hline $2572 \mathrm{C}>\mathrm{A}$ & 1 \\
$2361 \mathrm{G}>\mathrm{A}$ & 16 \\
GCGTGGACA & 1 \\
$2571 \mathrm{G}>\mathrm{A}$ & 1 \\
T751-I759>N & 1 \\
$2240-2252 \mathrm{Del}$ & 1 \\
$2237-2250>\mathrm{T}$ & 1 \\
$2240-2257 \mathrm{Del}$ & 1 \\
$2253-2276 \mathrm{Del}$ & 1 \\
2259 G $>$ A & 1
\end{tabular}

Del, deletion.

adenocarcinoma was significant $(\mathrm{P}<0.001)$; the mutation rate in female patients $(65.53 \%, 405 / 618)$ was distinctly increased compared with that in males $(39.80 \%, 283 / 711)$. However, there was no difference in the mutation rate between patients $\geq 60$ and $<60(\mathrm{P}=0.145)$.

EGFR mutation in squamous cell carcinoma. Similar results were also observed in squamous cell carcinoma (Table VIII); among 219 squamous cell carcinoma cases, including 187 male and 32 female patients, there was a significant difference in the mutation rate between male $(5.35 \%, 10 / 187)$ and female $(28.13 \%, 9 / 32)$ patients $(\mathrm{P}<0.001)$, whereas there was no difference between patients $\geq 60$ and $<60(\mathrm{P}=1.00)$.

EGFR mutation in adenosquamous cell carcinoma. From a total of 19 adenosquamous cell carcinoma cases, 9 exhibited EGFR mutations, including 4 cases with 19Del, 4 cases with L858R and 1 case with both 19Del and L858R.

Associations between sample type and detection methods. The sample types in all cases were classified into 5 types according to their origin and extraction method (Fig. 2). Paraffin-embedded biopsy sections accounted for 939 cases; paraffin-embedded samples from surgical resection accounted for 372 cases; paraffin-embedded hydrothorax or ascitic 


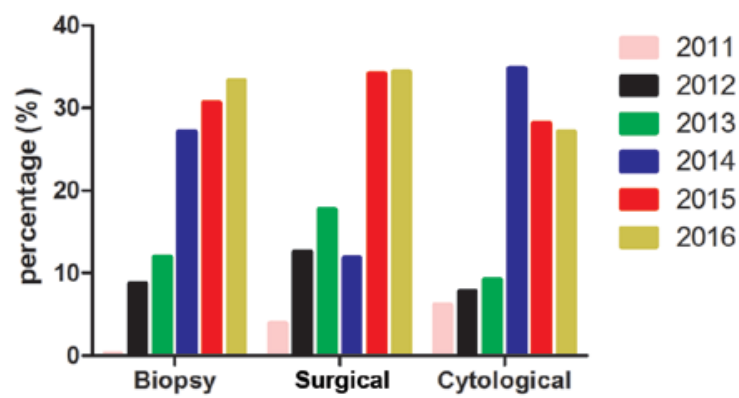

Figure 2. Summary of the sample types used in the present study. All samples were classified into 5 types: Biopsy samples, surgical samples, cytological samples, fresh tissue and samples of unclear origin. As no significant difference was identified between the latter two categories, only the three main types are depicted. The total sample amounts in 2011 and 2016 were estimated by extrapolation.

fluid samples accounted for 270 cases; fresh tissue samples accounted for 9 cases; and 6 samples were of unknown origin. Samples in 2014, 2015, 2016 year presented an obvious increasing tendency (samples in 2016 only collected up to June), in which paraffin-embedded biopsy sections were the majority in every year, making up $2 / 3$ of all samples (939/1596). No differences were observed in the consistency between sample types $(\mathrm{P}=0.052)$.

EGFR mutation characteristics of retrospective cases. A total of 29 cases were re-examined. Among these cases, 1 case revealed a different pathological type, from adenocarcinoma to adenosquamous cell carcinoma. A total of 9 cases exhibited mutation type variation; 1 case changed from all exons intact to 19Del, whereas 1 case changed from 19Del to wild-type, and 7 cases exhibited multiple mutations whereas they were originally detected as single-mutation or wild-type samples (Table IX). The 29 samples were classified depending on the consistency and whether the sample type in the first instance was consistent with the second. The results were statistically insignificant (Table $\mathrm{X}$ ), suggesting that different gene detection results did not result from the different sample types.

\section{Discussion}

Reflecting the heterogeneity of NSCLC, molecularly targeted therapy requires that different patients should receive different treatment strategies. Patients with EGFR mutations respond well to tyrosine kinase inhibitors, whereas patients with wild-type EGFR genes respond poorly (17-19). Chu et al (20) demonstrated that the rate of EGFR-TKI effectiveness against tumors with EGFR mutations (80\%) was increased compared with tumors with EGFR wild-type (12.5\%). Gefitinib may also be a more optimal treatment for tumors with common EGFR mutations than for tumors with rare EGFR mutations based on progression-free and overall survival (OS) (21). In addition, the improvement in OS is more evident for first-line afatinib than conventional chemotherapy for tumors with EGFR exon 19 mutations, whereas this does not occur for tumors with exon 21 mutations (17). Thus, an efficient, economic and convenient detection method for EGFR mutations may assist in the development of personalized treatment regimes. 
Table VIII. Characteristics and EGFR gene mutation rate of patients with squamous cell carcinoma.

\begin{tabular}{|c|c|c|c|c|c|c|c|c|}
\hline \multirow[b]{2}{*}{ Characteristic } & \multicolumn{6}{|c|}{ EGFR gene mutation, $\mathrm{n}$} & \multirow[b]{2}{*}{ Detected number } & \multirow[b]{2}{*}{ Mutation rate, $\%$} \\
\hline & 19Del & L858R & 19Del + L858R & 19Del - T790M & 20Ins & Total & & \\
\hline \multicolumn{9}{|l|}{ Sex } \\
\hline Male & 5 & 5 & 0 & 0 & 0 & 10 & 187 & $5.35^{\mathrm{a}}$ \\
\hline Female & 2 & 5 & 0 & 0 & 2 & 9 & 32 & 28.13 \\
\hline \multicolumn{9}{|l|}{ Age, years } \\
\hline$<60$ & 2 & 2 & 0 & 0 & 0 & 4 & 59 & $6.78^{\mathrm{b}}$ \\
\hline$\geq 60$ & 5 & 8 & 0 & 0 & 2 & 15 & 160 & 9.38 \\
\hline Total & 7 & 10 & 0 & 0 & 2 & 19 & 219 & 8.68 \\
\hline
\end{tabular}

${ }^{a} \chi^{2}=17.892, P<0.001$ vs. female patients; ${ }^{b} \chi^{2}=0.381, P=0.787$ vs. $\geq 60$. EGFR, epidermal growth factor receptor; Del, deletion; Ins, insertion.

Table IX. Results of the re-inspection of 9 cases.

\begin{tabular}{lccccc}
\hline Detection instance & \multicolumn{4}{c}{ Epidermal growth factor receptor mutation type } \\
\hline First & 19Del & WT & WT & L858R & 19Del \\
Second & WT & 19Del & 19Del + T790M & L858R + T790M & 19Del + T790M \\
Cases, $n$ & 1 & 1 & 2 & 3 & 2 \\
\hline
\end{tabular}

WT, wild-type; Del, deletion.

Table X. Influence of different sample type on the consistency of the result over multiple assessments.

\begin{tabular}{lccc}
\hline & \multicolumn{2}{c}{ Consequence, $\mathrm{n}$} & \\
\cline { 2 - 3 } Sample types & Same outcome & Different outcome & Total \\
\hline Total & 20 & 9 & 29 \\
Same type & 10 & 5 & 15 \\
Different type & 10 & 4 & 14 \\
\hline
\end{tabular}

Consistency of same vs. different sample type, $\chi^{2}=0.077, \mathrm{P}=1.00$.

In the present study, two methods were applied to detect EGFR gene mutations. Direct sequencing was perceived as a standard reference method to compare with ARMS; however, direct sequencing is hyposensitive and time consuming ( $\sim 2$ days for one detection), and these shortcomings prevent its widespread application in clinical and laboratory settings. On the contrary, ARMS is a time-saving method with high sensitivity (30\% vs. $1 \%$ ) (22).

The number of patients diagnosed with NSCLC at The First Affiliated Hospital of Wenzhou Medical University increased each year between 2011 and 2016. This may have been caused by a deteriorating living environment, including haze, sand storms and occupational exposure, and unhealthy lifestyle factors, including smoking. The increasing diagnosis rates may also result from improved detection techniques. Among the 1,596 cases, the total EGFR mutation frequency was $45.55 \%$ ( 727 cases), a frequency increased compared with that observed by Ueno et al (23) (33\%), possibly as a result of the different sex distribution of the patients or the misdiagnosis of squamous cell carcinoma.

Among patients with adenocarcinoma, the low proportion of female patients (male/female, 707/608) may have resulted in an EGFR mutation frequency which was reduced relative to other studies, including those by Wang et al (24) (63.1\% vs. $51.77 \%$ in the present study). The EGFR genes of female patients with adenocarcinoma were more susceptible to mutation in a previous study (25), which was consistent with the present study (female vs. male patients, $\mathrm{P}<0.01$ ). It has been hypothesized that women are more sensitive to the carcinogens from cigarette smoke (26), whereas a number of studies conclude that there is no association between smoking status and EGFR gene mutations in lung adenocarcinoma $(27,28)$. Although a number of previous studies have reported the inverse outcome, non-smoking patients develop adenocarcinoma with a higher EGFR gene mutation frequency $(25,29-31)$. We hypothesize that the target gene for the carcinogens in tobacco is not EGFR, but an as-yet unidentified gene.

Squamous cell carcinoma, a type of NSCLC with the highest morbidity after adenocarcinoma, exhibited a relatively high EGFR mutation frequency in the present study (15.55\%). The results were consistent with a previous study that identified a higher mutation frequency in female patients compared with male patients with squamous cell carcinoma (23). Furthermore, Ueno et al and Chen et al $(23,32)$ concluded that there was no distinct association between EGFR mutation frequency and age; the results of the present study were consistent with this 
hypothesis. Among the 1,596 patients, 19 patients presented with adenosquamous cell carcinoma, a pathologically mixed tumor of cells from both adenocarcinoma and squamous cell carcinoma. Due to its rarity, there are a low number of reports concerning this phenomenon in terms of its EGFR gene mutation status (33-35), and it remains unknown whether EGFR-TKIs are suitable for the treatment of patients with adenosquamous cell carcinoma with mutant EGFR or normal EGFR genes.

There was consistency $(89.21 \%)$ between the standard reference method of direct sequencing and ARMS among the 1,140 cases detected using both methods. Additionally, the direct sequencing method has relatively low sensitivity $(36,37)$, requiring $200 \mathrm{ng}$ of DNA and a mutation in $>20 \%$ of the sample (38), whereas ARMS may detect $1 \%$ mutant DNA in a background of $99 \%$ normal DNA in a 10 ng DNA sample. The existing ARMSDx ${ }^{\circledR}$ EGFR 29 Mutations Detection kit was able to detect 29 types of mutation and amplified only the mutant sequences, demonstrating that the kit is more sensitive than direct sequencing, which amplifies the whole sequence of the target gene (39). Thus, ARMS may be a viable alternative for patients who have not undergone surgery, as a smaller sample is required.

We hypothesized that the optimal sample type for the two methods may differ, as different sample types may suit different detection methods. Therefore, a $\chi^{2}$ test was used to detect discrepancies in formalin-fixed paraffin-embedded tissue samples from biopsy and surgery, which accounted for $\sim 1 / 2$ of all samples. The outcome revealed a trending, but non-significant tendency towards a difference in the accuracy of biopsy and surgery materials between methods $(\mathrm{P}=0.052)$. Theoretically, the samples obtained from surgery include more tissue compared with biopsy samples. The process of fixing samples with formalin and embedding in paraffin may cause DNA degradation (40), which may cause a decreased detectability in samples from biopsy when using a sequencing method, due to the reduced availability of tissue or DNA. However, this tendency was not reflected in the present study, possibly due to the relatively small size of surgically collected samples.

The ARMS method is currently used for routine clinical detection, treatment guidelines and laboratory research; it is associated with relatively rapid processing, accuracy, decreased cost and decreased sample size demand compared with direct sequencing. However, certain drawbacks of the estimation of mutation status by ARMS were identified in the present study, as 33 cases that were identified as wild-type using ARMS were identified as EGFR mutation-positive with direct sequencing, whereas 55 cases revealed the opposite result, likely reflective of insufficient sample volume for direct sequencing. It was also verified that the T790M mutation, which is associated with drug resistance $(41,42)$, was more likely to be detected in the patients subsequent to treatment, with 7 of the 9 cases re-tested exhibiting the $\mathrm{T} 790 \mathrm{M}$ mutant.

The present study verified the results of previous studies using large amounts of data, which comparatively expound on the application of ARMS for EGFR mutant detection. The deficiency of the present study is the lack of additional research in treatment and prognosis, which would generate more promising results.

\section{Acknowledgements}

The present study was supported by grants from the Natural Science Foundation of Zhejiang Province (grant no. LY16H160047), the Scientific Research Foundation of Wenzhou, Zhejiang Province, China (grant no. Y20130073), the National Natural Sciences Foundation of China (grant nos. 81201589 and 81472651) and the Health and Family Planning Commission of Zhejiang Province (grant no. 2013ZDA014).

\section{References}

1. Siegel RL, Miller KD and Jemal A: Cancer statistic, 2015. CA Cancer J Clin 65: 5-29, 2015.

2. Molina JR, Yang P, Cassivi SD, Schild SE and Adjei AA: Non-small cell lung cancer: Epidemiology, risk factors, treatment and survivorship. Mayo Clin Proc 83: 584-594, 2008.

3. Zhou C, Wu YL, Chen G, Feng J, Liu XQ, Wang C, Zhang S, Wang J, Zhou S, Ren S, et al: Erlotinib versus chemotherapy as first-line treatment for patients with advanced EGFR mutation-positive non-small-cell lung cancer (OPTIMAL, CTONG-0802): A multicentre, open-label, randomised, phase 3 study. Lancet Oncol 12: 735-742, 2011.

4. Tang Y, Wang WY, Zheng K, Jiang L, Zou Y, Su XY, Chen J, Zhang WY and Liu WP: EGFR mutations in non-small cell lung cancer: An audit from West China Hospital. Expert Rev Mol Diagn 16: 915-919, 2016.

5. Minna JD, Fong K, Zöchbauer-Müller S and Gazdar AF: Molecular pathogenesis of lung cancer and potential translational applications. Cancer J 8 (Suppl 1): S41-S46, 2002.

6. Villaflor V, Won B, Nagy R, Banks K, Lanman RB, Talasaz A and Salgia R: Biopsy-free circulating tumor DNA assay identifies actionable mutations in lung cancer. Oncotarget 7: 66880-66890, 2016.

7. Olayioye MA, Neve RM, Lane HA and Hynes NE: The ErbB signaling network: Receptor heterodimerization in development and cancer. EMBO J 19: 3159-3167, 2000.

8. Charpidou A, Blatza D, Anagnostou V and Syrigos KN: Review. EGFR mutations in non-small cell lung cancer-clinical implications. In vivo 22: 529-536, 2008.

9. Maemondo M, Inoue A, Kobayashi K, Sugawara S, Oizumi S, Isobe H, Gemma A, Harada M, Yoshizawa H, Kinoshita I, et al: Gefitinib or chemotherapy for non-small-cell lung cancer with mutated EGFR. N Engl J Med 362: 2380-2388, 2010.

10. Mitsudomi T, Morita S, Yatabe Y, Negoro S, Okamoto I, Tsurutani J, Seto T, Satouchi M, Tada H, Hirashima T, et al: Gefitinib versus cisplatin plus docetaxel in patients with non-small-cell lung cancer harbouring mutations of the epidermal growth factor receptor (WJTOG3405): An open label, randomised phase 3 trial. Lancet Oncol 11: 121-128, 2010.

11. Han JY, Park K, Kim SW, Lee DH, Kim HY, Kim HT, Ahn MJ, Yun T, Ahn JS, Suh C, et al: First-SIGNAL: First-line single-agent iressa versus gemcitabine and cisplatin trial in never-smokers with adenocarcinoma of the lung. J Clin Oncol 30: 1122-1128, 2012.

12. Wang CC, Chao KH, Chen YL, Chang JG and Wu SM: Capillary electrophoretic genotyping of epidermal growth factor receptor for pharmacogenomic assay of lung cancer therapy. J Chromatogra A 1256: 276-279, 2012.

13. Liu W, Smith DI, Rechtzigel KJ, Thibodeau SN and James CD: Denaturing high performance liquid chromatography (DHPLC) used in the detection of germline and somatic mutations. Nucleic Acids Res 26: 1396-1400, 1998.

14. Do H, Krypuy M, Mitchell PL, Fox SB and Dobrovic A: High resolution melting analysis for rapid and sensitive EGFR and KRAS mutation detection in formalin fixed paraffin embedded biopsies. BMC Cancer 8: 142, 2008.

15. Tuononen K, Maki-Nevala S, Sarhadi VK, Wirtanen A, Rönty M, Salmenkivi K, Andrews JM, Telaranta-Keerie AI, Hannula S, Lagström S, et al: Comparison of targeted next-generation sequencing (NGS) and real-time PCR in the detection of EGFR, KRAS and BRAF mutations on formalin-fixed, paraffin-embedded tumor material of non-small cell lung carcinoma-superiority of NGS. Genes Chromosomes Cancer 52: 503-511, 2013. 
16. Marchetti A, Martella C, Felicioni L, Barassi F, Salvatore S, Chella A, Camplese PP, Iarussi T, Mucilli F, Mezzetti A, et al: EGFR mutations in non-small-cell lung cancer: Analysis of a large series of cases and development of a rapid and sensitive method for diagnostic screening with potential implications on pharmacologic treatment. J Clin Oncol 23: 857-865, 2005.

17. Yang JC, Wu YL, Schuler M, Sebastian M, Popat S, Yamamoto N, Zhou C, Hu CP, O'Byrne K, Feng J, et al: Afatinib versus cisplatin-based chemotherapy for EGFR mutation-positive lung adenocarcinoma (LUX-Lung 3 and LUX-Lung 6): Analysis of overall survival data from two randomised, phase 3 trials. Lancet Oncol 16: 141-151, 2015.

18. Rosell R, Carcereny E, Gervais R, Vergnenegre A, Massuti B, Felip E, Palmero R, Garcia-Gomez R, Pallares C, Sanchez JM, et al: Erlotinib versus standard chemotherapy as first-line treatment for European patients with advanced EGFR mutation-positive non-small-cell lung cancer (EURTAC): A multicentre, open-label, randomised phase 3 trial. Lancet Oncol 13: 239-246, 2012.

19. Wu YL, Zhou C, Hu CP, Feng J, Lu S, Huang Y, Li W, Hou M, Shi JH, Lee KY, et al: Afatinib versus cisplatin plus gemcitabine for first-line treatment of Asian patients with advanced non-small-cell lung cancer harbouring EGFR mutations (LUX-Lung 6): An open-label, randomised phase 3 trial. Lancet Oncol 15: 213-222, 2014

20. Chu H, Zhong C, Xue G, Liang X, Wang J, Liu Y, Zhao S, Zhou Q and Bi J: Direct sequencing and amplification refractory mutation system for epidermal growth factor receptor mutations in patients with non-small cell lung cancer. Oncol Rep 30: 2311-2315, 2013.

21. Watanabe S, Minegishi Y, Yoshizawa H, Maemondo M, Inoue A, Sugawara S, Isobe $\mathrm{H}$, Harada M, Ishii Y, Gemma A, et al: Effectiveness of gefitinib against non-small-cell lung cancer with the uncommon EGFR mutations G719X and L861Q. J Thorac Oncol 9: 189-194, 2014

22. Liu Y, Liu B, Li XY, Li JJ, Qin HF, Tang CH, Guo WF, $\mathrm{Hu} \mathrm{HX}$, Li S, Chen CJ, et al: A comparison of ARMS and direct sequencing for EGFR mutation analysis and tyrosine kinase inhibitors treatment prediction in body fluid samples of non-small-cell lung cancer patients. J Exp Clin Cancer Res 30 $111,2011$.

23. Ueno T, Toyooka S, Suda K, Soh J, Yatabe Y, Miyoshi S, Matsuo K and Mitsudomi T: Impact of age on epidermal growth factor receptor mutation in lung cancer. Lung cancer 78: 207-211, 2012.

24. Wang R, Zhang Y, Pan Y, Li Y, Hu H, Cai D, Li H, Ye T, Luo X, Zhang Y, et al: Comprehensive investigation of oncogenic driver mutations in Chinese non-small cell lung cancer patients. Oncotarget 6: 34300-34308, 2015.

25. Chen ZY, Zhong WZ, Zhang XC, Li Y, Hu H, Cai D, Li H, Ye T, Luo X, Zhang Y, et al: EGFR mutation heterogeneity and the mixed response to EGFR tyrosine kinase inhibitors of lung adenocarcinomas. Oncologist 17: 978-985, 2012.

26. International Early Lung Cancer Action Program I, Henschke CI, Yip R and Miettinen OS: Women's susceptibility to tobacco carcinogens and survival after diagnosis of lung cancer. JAMA 296: 180-184, 2006.

27. Bain C, Feskanich D, Speizer FE, Thun M, Hertzmark E, Rosner BA and Colditz GA: Lung cancer rates in men and women with comparable histories of smoking. J Natl Cancer Inst 96: 826-834, 2004

28. Chan-Yeung M and Dimich-Ward H: Respiratory health effects of exposure to environmental tobacco smoke. Respirology 8: $131-139,2003$
29. Greenhalgh J, Dwan K, Boland A, Bates V, Vecchio F, Dundar Y, Jain $P$ and Green JA: First-line treatment of advanced epidermal growth factor receptor (EGFR) mutation positive non-squamous non-small cell lung cancer. Cochrane Database Syst Rev 25: CD010383, 2016.

30. Jida M, Toyooka S, Mitsudomi T, Takano T, Matsuo K, Hotta K, Tsukuda K, Kubo T, Yamamoto H, Yamane M, et al: Usefulness of cumulative smoking dose for identifying the EGFR mutation and patients with non-small-cell lung cancer for gefitinib treatment. Cancer Sci 100: 1931-1934, 2009.

31. Midha A, Dearden S and McCormack R: EGFR mutation incidence in non-small-cell lung cancer of adenocarcinoma histology: A systematic review and global map by ethnicity (mutMapII). Am J Cancer Res 5: 2892-2911, 2015.

32. Chen YM, Lai CH, Rau KM, Huang CH, Chang HC, Chao TY, Tseng CC, Fang WF, Chen YC, Chung YH, et al: Advanced non-Small cell lung cancer patients at the extremes of age in the era of epidermal growth factor receptor tyrosine kinase inhibitors. Lung cancer 98: 99-105, 2016.

33. Filosso PL, Ruffini E, Asioli S, Giobbe R, Macri L, Bruna MC, Sandri A and Oliaro A: Adenosquamous lung carcinomas: A histologic subtype with poor prognosis. Lung Cancer 74: 25-29, 2011.

34. Gawrychowski J, Brulinski K, Malinowski E and Papla B: Prognosis and survival after radical resection of primary adenosquamous lung carcinoma. Eur J Cardiothorac Surg 27: 686-692, 2005.

35. Riquet M, Perrotin C, Lang-Lazdunski L, Hubsch JP, Dujon A, Manac'h D, Le Pimpec Barthes F and Briere J: Do patients with adenosquamous carcinoma of the lung need a more aggressive approach? J Thorac Cardiovasc Surg 122: 618-619, 2001.

36. Li J, Wang L, Mamon H, Kulke MH, Berbeco $\mathrm{R}$ and Makrigiorgos GM: Replacing PCR with COLD-PCR enriches variant DNA sequences and redefines the sensitivity of genetic testing. Nature medicine 14: 579-584, 2008.

37. Ellison G, Donald E, McWalter G, Knight L, Fletcher L, Sherwood J, Cantarini M, Orr M and Speake G: A comparison of ARMS and DNA sequencing for mutation analysis in clinical biopsy samples. J Exp Clin Cancer Res 29: $132,2010$.

38. Li C, Wu J, Wang $\mathrm{Z}$ and Feng J: A comparison of direct sequencing and ARMS assay performance in EGFR mutation analysis of non-small cell lung cancer patients. Zhongguo Fei Ai Za Zhi 17: 606-611, 2014 (In Chinese).

39. Jiang J, Wang C, Yu X, Sheng D, Zuo C, Ren M, Wu Y, Shen J, Jin M and Xu S: PCR-sequencing is a complementary method to amplification refractory mutation system for EGFR gene mutation analysis in FFPE samples. Exp Mol Pathol 99: 581-589, 2015.

40. von Ahlfen S, Missel A, Bendrat K and Schlumpberger M: Determinants of RNA quality from FFPE samples. PLoS One 2: e1261, 2007.

41. Hata A, Katakami N, Yoshioka H, Takeshita J, Tanaka K, Nanjo S, Fujita S, Kaji R, Imai Y, Monden K, et al: Rebiopsy of non-small cell lung cancer patients with acquired resistance to epidermal growth factor receptor-tyrosine kinase inhibitor: Comparison between T790M mutation-positive and mutation-negative populations. Cancer 119: 4325-4332, 2013.

42. Zhu VW, Upadhyay D, Schrock AB, Gowen K, Ali SM and Ou SH: TPD52L1-ROS1, a new ROS1 fusion variant in lung adenosquamous cell carcinoma identified by comprehensive genomic profiling. Lung cancer 97: 48-50, 2016. 